\title{
Falls prevention in the elderly: translating evidence into practice
}

\author{
James KH Luk *, TY Chan, Daniel KY Chan
}

\section{A B S T R A C T}

Falls are a common problem in the elderly. A common error in their management is that injury from the fall is treated, without finding its cause. Thus a proactive approach is important to screen for the likelihood of fall in the elderly. Fall assessment usually includes a focused history and a targeted examination. Timed up-and-go test can be performed quickly and is able to predict the likelihood of fall. Evidence-based fall prevention interventions include multi-component group or home-based exercises, participation in Tai Chi, environmental modifications, medication review, management of foot and footwear problems, vitamin D supplementation, and management of cardiovascular problems. If possible, these are best implemented in the form of multifactorial intervention. Bone health enhancement for

This article was published on $27 \mathrm{Feb}$ 2015 at www.hkmj.org. residential care home residents and appropriate community patients, and prescription of hip protectors for residential care home residents are also recommended. Multifactorial intervention may also be useful in a hospital and residential care home setting. Use of physical restraints is not recommended for fall prevention.

\section{Hong Kong Med J 2015;21:165-71}

DOI: 10.12809/hkmj144469

1 JKH Luk *, FHKCP, FHKAM (Medicine)

${ }^{2}$ TY Chan, FHKCP, FHKAM (Medicine)

${ }^{3}$ DKY Chan, MD, FRACP

Department of Medicine and Geriatrics, Fung Yiu King Hospital, Hong Kong

2 Department of Medicine and Geriatrics, Kwong Wah Hospital, Yaumatei, Hong Kong

${ }^{3}$ Faculty of Medicine, University of New South Wales, Ingham Institute;

Aged Care \& Rehab, Bankstown Hospital, Australia

* Corresponding author: lukkh@ha.org.hk

\section{Introduction}

Falls and imbalance occur commonly in the elderly and fall/instability is indeed one of the 'giants' in geriatric medicine. ${ }^{1} \mathrm{~A}$ fall is often defined as an event that results in the patient or a body part of the patient coming to rest inadvertently on the ground or other surface lower than the body. ${ }^{2}$ In Hong Kong, the prevalence in the elderly of having at least one fall in the preceding 12 months is between $18 \%$ and $19.3 \%$, with $75.2 \%$ sustaining injuries and $7.2 \%$ having a serious injury. ${ }^{3,4}$ Those who fall have significantly more hospitalisations and clinic visits as well as accident and emergency department visits than those who do not. Fear of falling, loss of confidence in walking, social isolation, and depression can also occur. Fall is a predictor for decreased functional state and risk factor for institutionalisation, ${ }^{5}$ and the elderly who are prone to falling consume more health care resources than non-fallers each year. ${ }^{6}$

\section{Pitfalls in fall management}

Despite the potentially severe consequences of falls, under-reporting by the elderly is common.? Individuals may attribute falling to the ageing process or they may not report falls because of the fear of being restricted in their activities or being institutionalised following a fall. Some older people, especially those with cognitive impairment, may forget the event and consequently fail to inform the health care team. Alternatively, in the absence of an obvious injury, physicians may be unaware of falls. A drawback to the management of falls is that the consequences, such as fractures or head injuries, are treated without finding the cause of the fall. Unless all the underlying risk factors are addressed, falls are very likely to recur.

\section{Knowing the risk/precipitating factors for falls}

The first step in fall prevention is to identify the risk or precipitating factors for falls. Age by itself is an important risk factor, but not the only one. Falls in the elderly are often due to the interaction of multiple risk factors. One practical way to help clinicians identify risk or precipitating factors is to use a mnemonic. One such mnemonic is shown in the Table. ${ }^{8}$

\section{Fall assessment}

As falls are usually under-reported, a proactive approach is to ask "Have you had a fall in the past 6 months?" at every encounter with an elderly patient. Initial medical assessment involves a focused history-taking, detailing the circumstances of fall, precipitating factors, and consequences. A witness can be helpful to identify unrecognised 


\section{預防老年人跌倒：從證據到實踐 陸嘉熙、陳德揚、陳錦賢}

跌倒是老年人常見的問題。醫治因跌倒造成的損傷, 卻沒有找出導致 跌倒的原因, 是經常會犯的錯誤。採取積極態度找出老年人跌倒的可 能性相當重要。評估老年人跌倒通常包括了解其病史和進行針對性 檢查。「起立一行走計時測試」（timed up-and-go test）可以快速進 行, 並能預測老年人跌倒的機會率。歸納相關實證研究後得出預防跌 倒的方法包括綜合性運動的集體鍛鍊或家居練習、打太極拳、環境調 適或改裝、用藥風險評估、矯正腳部和鞋子的問題、維生素 $\mathrm{D}$ 的補充 和心血管疾病的處理。可以的話, 最好綜合多方面的因素來處理跌倒 的方法。建議為居住安老院和適合的社區老年人提升其骨骼健康，以 及為居住安老院的老年人提供顝關節保護器。多因素干預可能對醫院 和居住安老院的老年人有用, 但不建議為預防跌倒而使用身體約束。 syncope. Other relevant history includes living environment, social support, past medical illnesses, medication, history of falls or near falls, and mobility and functional status. Comprehensive geriatric assessment should follow documentation of history. ${ }^{9}$ Testing of gait, balance, and lower limb and joint function, alongside cardiovascular and neurological examination should be performed where relevant. Postural blood pressure, vision, feet, and footwear should also be checked. Measurement of postural blood pressure requires a wait of at least 3 minutes between sitting and standing (or lying and sitting), and is often omitted or not done properly. Simple bedside investigations such as electrocardiography should be performed as arrhythmia may be the cause of falls due to syncope. Further investigations should be guided by the history and examination.

One simple screening test for mobility is the timed up-and-go test. ${ }^{10}$ The patient is timed while rising from a 46-cm high armchair, walking 3 metres, turning around, and returning to sit in the chair (total 6 metres). The assessment should be repeated with a walking aid if the patient is found to be unsteady. Patients who require more than 20 seconds to complete the task are at risk of fall. It is prudent to refer 'fallers' with multiple risk factors to geriatricians for professional assessment and management. Risk factors, once identified, should then be managed with inter-disciplinary intervention to reduce the risks as soon as possible. For example, if impaired vision due to cataract is identified, an expedited eye consultation and cataract treatment is desirable to reduce the chance of recurrent falls.

\section{Practical evidence-based strategies in fall prevention}

\section{Exercise}

Multi-component exercises, including strength, endurance and balance training, either in a group or home-based, have been shown to reduce both rate and risk of falling. ${ }^{11}$ The exercises need to be of sufficient intensity to improve muscle strength. Balance retraining appears to be the more important component of any exercise programme designed to decrease falls. ${ }^{12}$ The balance training can either be specific dynamic balance retraining exercises or a component of a movement programme such as Tai Chi. ${ }^{13}$ Exercises should be regular and sustainable, and be a part of multifactorial intervention (MFI; see below). One should be aware that prescribing inappropriate exercise may increase falls in the elderly.

\section{Tai Chi}

The anecdote of Tai Chi in fall prevention is generally well known to the public. Similar to multicomponent exercises, Tai Chi reduces both the rate of fall and falling risk according to a Cochrane Review. ${ }^{11}$ Wolf et $\mathrm{al}^{14}$ also reported the benefit of

TABLE. Mnemonic (A E I O U, A B B C C C) of risk or precipitating factors for falls ( $A$ is shared between vowels and $A B C)^{8}$

\begin{tabular}{ll}
\hline A & Anti-depressants, anti-psychotics, anti-cholinergics, anti-epileptics, antihypertensives \\
E & Environmental hazards, eg home, outdoors \\
I & Infectious diseases, eg urinary tract infection, chest infection, and others \\
O & Osteoarthritis and musculoskeletal problems \\
U & Unwell patients are more prone to falls \\
B & $\begin{array}{l}\text { Blindness and visual impairment, eg refractive, cataract, macular degeneration, glaucoma, visual field defect, hemi- } \\
\text { spatial neglect after cortical stroke }\end{array}$ \\
B & Biochemical abnormalities, eg hyponatraemia, hypokalaemia, hypoglycaemia \\
C & Cardiovascular problems, eg postural hypotension, heart block, arrhythmias, carotid sinus hypersensitivity \\
C & Central nervous system or peripheral nervous system disorders, Parkinsonism \\
C & Cognitive impairment, eg dementia, delirium \\
\hline
\end{tabular}


10-form Tai Chi in a randomised controlled trial (RCT). Tai Chi is a combination of strength and balance training, with a certain aerobic element. ${ }^{15}$ In Hong Kong, most people practise the full form that should theoretically be at least effective, if not better. This can be promoted as a territory-wide health recommendation. Nonetheless, not all Tai Chi programmes improve balance. One local RCT revealed no difference in the number of falls between a Tai Chi group and controls after 12 months. ${ }^{16}$

\section{Environmental interventions}

Home modifications can effectively reduce risk of falls in the community, ${ }^{11}$ and include removal of floor mats, painting the edge of steps, reducing glare, installing handles, and improving lighting. Occupational therapists can provide expert advice in this area. For older people with fall risk who live at home, especially those who are usually alone, installation of a safety alarm is recommended so help can be summoned should an accident occur.

\section{Medication review}

Polypharmacy is common among older people who often have multiple co-morbidities, and is an independent variable that has been linked to falls in older people. ${ }^{17}$ Manydrugs, psychotropic medications and antihypertensive agents in particular, are related to falls. The use of psychotropic medication should be confined to patients who do not respond to nonpharmacological intervention and the lowest dosage should be prescribed. Periodic review of indications and side-effects should be undertaken: gradual withdrawal of psychotropic medication can reduce rate of falls in community-dwelling elderly people. ${ }^{11}$ Nonetheless drug withdrawal is a complicated intervention that should be implemented by an experienced clinician after carefully weighing the risks and benefits. A standardised and explicit medicine review tool such as the Beers Criteria for Potentially Inappropriate Medication Use in Older Adults and STOPP (Screening Tool of Older Person's potentially inappropriate Prescriptions) may be useful in reducing falls in older people but the effectiveness of these approaches has not been proven by RCTs. ${ }^{18,19}$ Although drug withdrawal is beneficial, studies that include RCTs show that many withdrawals (eg sleeping pills) are reversed and patients resume previous therapy. Ongoing monitoring is therefore essential. ${ }^{20}$

\section{Foot and footwear}

Foot and footwear problems are common but are often ignored. Footwear influences balance and risk of falls. High-heeled shoes have been shown to increase falls in older people. Anti-slip shoe devices effectively reduce outdoor falls in slippery conditions. ${ }^{21}$ A systematic review recommends that elderly individuals wear shoes with a low heel and firm slip-resistant soles, both inside and outside the home. ${ }^{22}$ Podiatrists, and prosthetics and orthotics professionals can give valuable advice in this respect. A recent RCT has shown that multifaceted podiatry intervention with foot orthoses, footwear advice, education, and foot and ankle exercises can reduce the rate of falls in community-dwelling older people. ${ }^{23}$

\section{Vitamin D supplement}

The benefit of vitamin $D$ in falls/fractures extends beyond improved bone health. Vitamin D can strengthen muscle and hence reduce falls. Metaanalysis has shown that supplemental vitamin D at a dose of 700 IU to 1000 IU a day reduces the risk of falling among older individuals by $19 \% .^{24}$ The current opinion is that in community-dwelling elderly, vitamin $\mathrm{D}$ supplementation reduces the rate of falls or risk of falling in a subgroup of people with low vitamin $\mathrm{D}$ levels but its benefit is absent in people without deficiency. ${ }^{11}$ In the institutionalised elderly, vitamin D supplementation appears to be more effective in reducing falls and the recommendation is to prescribe vitamin $\mathrm{D}$ with or without calcium supplements to older people with low vitamin D levels or those who are institutionalised. ${ }^{11}$ Despite these recommendations, most studies have been conducted in western countries that experience a quite different duration and intensity of sunshine to Hong Kong. Whether the benefit of vitamin D in fall prevention applies equally to Hong Kong Chinese population is not known. Most public hospital laboratories in Hong Kong do not have the means to investigate vitamin D levels and clinicians are required to send blood samples to private laboratories for vitamin D level assay at a cost. Thus in the public health sector, mass screening of the elderly for vitamin $D$ deficiency prior to supplementation is impractical. The pragmatic approach is to encourage a healthy balanced diet that is rich in vitamin D. For older people who are at risk of fall, especially those in residential care home for the elderly ( $\mathrm{RCHE})$, a dose of 800 IU of vitamin D3 per day with or without calcium supplementation is recommended, provided there is no contra-indication. ${ }^{11}$ The clinician should also ask whether the older person is taking any overthe-counter vitamin D-containing drugs before commencing supplementation, as excess vitamin D may result in hypercalcaemia.

\section{Correction of vision}

Poor visual acuity caused by presbyopia, cataract, macular degeneration or glaucoma, reduction in depth perception and contrast sensitivity are risk factors for falls. ${ }^{25}$ Maximising vision with cataract surgery is effective in fall prevention. In a UK RCT 
that compared fast-track ( 4 weeks) with routinequeue (12 months) first eye cataract surgery, a significant reduction in fall and fracture rate in 1 year was observed in the fast-track group. ${ }^{26}$ Another $\mathrm{RCT}$ by the same team showed that fast-track surgery ( 4 weeks) for the second eye in older people also produced a tendency to fewer falls compared with the routine queue (12 months) group. ${ }^{27}$ One should beware, though, that correction of vision may sometimes result in increased falls. One RCT showed that vision assessment and intervention may increase the risk of falls and fractures, possibly due to poor adjustment to new spectacles. ${ }^{28}$ Multifocal lenses may increase fall risk by reducing contrast sensitivity and depth perception in the lower visual field when mobilising. ${ }^{29}$ As such, older individuals should wear single lens glasses, especially when performing outdoor activities.

\section{Management of cardiovascular risk factors}

Cardiovascular investigations and interventions are indicated for those with fall related to syncope and orthostatic hypotension. Neurally mediated syndromes (carotid sinus hypersensitivity, vasovagal syndrome, orthostatic hypotension, postprandial hypotension), arrhythmias (sick sinus syndrome, severe heart block, tachyarrhythmia), and structural cardiac disease (valvular stenosis, hypertrophic obstructive cardiomyopathy, atrial myxoma, aortic dissection) are all risk factors for falls because they cause either attacks of syncope or transient hypotension (pre-syncope). ${ }^{30}$ Randomised controlled trials in older patients have shown that those with dual-chamber pacemaker implantation for cardio-inhibitory carotid sinus hypersensitivity had significantly fewer falls and fall-related injuries. $^{31,32}$ It is beyond the scope of this article to describe in detail the investigation and management of individual cardiovascular conditions. Referrals to cardiology colleagues are recommended for certain conditions such as arrhythmias when appropriate. Other conditions such as postural hypotension can usually be managed by a geriatrician.

\section{Multifactorial intervention}

A MFI programme is a set of interventions designed to address multiple elements of fall risk. ${ }^{33}$ The elements of MFI usually include multi-component exercises, medical assessment and management of falls, medication adjustment, vitamin D supplementation if appropriate, environmental modifications, and patient education. Since falls are often multifactorial in nature, MFI (rather than a singular approach) is more likely to be effective and is therefore recommended. The intervention can take the form of a general MFI or be an individualised MFI with tailor-made interventions based on specific individual needs. ${ }^{11}$ Most evidence to support MFI efficacy is in community-dwelling older people. In a community setting, general MFI can achieve a $24 \%$ to $31 \%$ reduction in fall risk, while individualised MFI may improve this figure to $27 \%$ to $41 \% .{ }^{10}$ Multifactorial intervention may not be effective in fall prevention in other settings, such as in the accident and emergency department. ${ }^{34} \mathrm{~A}$ recent Malaysian RCT has just been completed to determine whether MFI is appropriate in an Asian country; the results are pending. ${ }^{35}$

\section{Fracture reduction}

Fall-related fractures can be reduced by improving bone strength. Thus assessment of bone health should be performed in older people as part of the comprehensive assessment. If indicated clinically, bone mineral density assessment can be undertaken in patients at risk of fragility fracture. ${ }^{36}$ In addition to vitamin $\mathrm{D}$ and calcium supplementation, specific pharmacological treatment should be considered. The World Health Organization FRAX (Fracture Risk Assessment Tool) score can be used to guide treatment by calculating the 10-year osteoporotic fracture rate..$^{37}$ It is beyond the scope of this article to describe in detail the management of bone fragility.

Another means of fracture protection is the use of hip protectors. ${ }^{38}$ Most hip protector designs consist of two mechanically proven hard plastic cups or soft pads placed or sewn to each side of a panty. Compliance with their use has been a problem in most studies though, and rates varying from $31 \%$ to $68 \%$ have been reported, reducing in particular over time. $^{39}$ One local study reported overall compliance rates of $55 \%$ to $70 \%$ with an $82 \%$ relative risk reduction of hip fracture. ${ }^{40}$ In Hong Kong, the hot and humid weather makes wearing of hip protectors uncomfortable for a prolonged period of time. Nonetheless a small reduction in hip fracture risk was reported in a systematic review when hip protectors were used in a RCHE with risk ratio of 0.82 (confidence interval, 0.67-1.00). ${ }^{41}$ No evidence of such benefit was observed in a community setting, hence their use should probably be confined to the RCHE setting.

\section{Fall prevention in hospital and residential care home setting}

Multifactorial intervention in hospital and the $\mathrm{RCHE}$ has been shown in a systematic review to reduce rate of falls. ${ }^{42}$ The effective components were comprehensive assessment, staff education, assistive devices, and reduction of medications. Older patients or residents should be assessed individually to develop individualised MFI treatment plans. However, the use of screening tools for risk of fall is more controversial in the institutional setting. 
In Hong Kong, screening tools such as Morse Fall Scale and STRATIFY are mandated in many hospital wards, long-stay wards in particular, with the former more commonly used. ${ }^{43,44}$ To date though, there is no evidence to support their use in fall prevention in an institutional setting. An experienced nurse's clinical judgement is just as effective. ${ }^{45}$ In addition, a disadvantage of screening tools is that they predict fall due to physiological factors, not incidental falls (eg patient slipping or tripping) or unpredictable physiological falls (eg seizures, syncope). Other risk factors for falls such as "impaired judgement in patients with cognitive impairment" may also not be included in traditional screening tools. ${ }^{46}$

Health care providers in hospitals or RCHEs may employ physical restraints to older patients when they are at risk of falling or delirious although evidence suggests these are ineffective, not to mention undignified. ${ }^{47}$ Further, patients may fall more frequently and sustain more serious injuries. Restraints increase the risk of delirium in the hospital setting and the consequent immobilisation precipitates other problems such as pressure sores, respiratory complications, and death via strangulation and aspiration. Although some longstay hospitals and institutions in Hong Kong have implemented a restraint reduction programme, they remain commonly used in some institutional settings. ${ }^{48}$

Vitamin D can be considered for all older people who live in RCHEs where the prevalence of deficiency is high. Other strategies for fall prevention that have been used in institutional settings are a chair/bed alarm system, ultra-low beds, and changing of the floor surface from vinyl to carpet. Nevertheless the effectiveness of these methods has not been proven through RCTs. ${ }^{49}$

\section{Fall prevention in the cognitively impaired older people}

Although falls are common among the elderly, there is insufficient evidence to recommend MFI or single intervention for cognitively impaired older people in community, hospital, and RCHE settings. The elderly with dementia have often been excluded from large-scale studies of falls. During training for fall prevention, older patients may be required to learn exercise skills and remember instructions; impaired memory can affect the success of fall prevention. Another report concludes that intervention for fall prevention among cognitively impaired older people in RCHEs is ineffective. ${ }^{50}$ Nonetheless some studies have reported positive effects. A local retrospective study showed that older people with dementia can still benefit from rehabilitation. ${ }^{51}$ One meta-analysis showed that strategies to prevent falls and fractures in hospitals and RCHEs were not affected by cognitive impairment. ${ }^{52}$ Another study demonstrated that the number of falls in psychogeriatric RCHE residents could be reduced by a targeted MFI. ${ }^{53}$ More studies are required to determine the optimum fall prevention strategies for older people with dementia.

\section{Conclusion}

Evidence-based interventions include multicomponent group or home-based exercises, Tai Chi, environmental modifications, medication review, management of foot and footwear problems, vitamin D supplementation, and addressing cardiovascular problems. If possible, these are best implemented in the form of MFI. Bone health enhancement for RCHE and appropriate community patients and prescription of hip protectors for RCHE patients are also recommended. A MFI programme may also be useful in the hospital and RCHE setting. Use of physical restraints is not recommended for fall prevention. More high-quality studies are required to examine fall prevention for older people with cognitive impairment. Modern technology for fall prevention, such as movement alarms and sensor technology, should also be further explored.

\section{References}

1. Willeboordse F, Hugtenburg JG, van Dijk L, et al. OptiMed: the effectiveness of optimised clinical medication reviews in older people with 'geriatric giants' in general practice; study protocol of a cluster randomised controlled trial. BMC Geriatr 2014;14:116.

2. Nevitt MC, Cummings SR, Hudes ES. Risk factors for injurious falls: a prospective study. J Gerontol 1991;46:M164-70.

3. Chu LW, Chi I, Chiu AY. Falls and fall-related injuries in community-dwelling elderly persons in Hong Kong: a study on risk factors, functional decline, and health services utilization after falls. Hong Kong Med J 2007;13(Suppl 1):S8-12.

4. Chu LW, Chi I, Chiu AY. Incidence and predictors of falls in the Chinese elderly. Ann Acad Med Singapore 2005;34:6072.

5. Luk JK, Chiu PK, Chu LW. Factors affecting institutionalization in older Hong Kong Chinese patients after recovery from acute medical problems. Arch Gerontol Geriatr 2009;49:e110-4.

6. Chu LW, Chiu AY. Chi I. Falls and subsequent health service utilization in community-dwelling Chinese older adults. Arch Gerontol Geriatr 2008;46:125-35.

7. Hill AM, Hoffmann T, Hill K, et al. Measuring falls events in acute hospitals-a comparison of three reporting methods to identify missing data in the hospital reporting system. J Am Geriatr Soc 2010;58:1347-52.

8. Chan DK. Chan's practical geriatrics. 2nd ed. Brookvale, NSW: BA Printing \& Publishing Services; 2009.

9. Luk JK, Or KH, Woo J. Using the comprehensive geriatric assessment technique to assess elderly patients. Hong Kong Med J 2000;6:93-8.

10. Podsiadlo D, Richardson S. The timed "Up \& Go": a test of basic functional mobility for frail elderly persons. J Am Geriatr Soc 1991;39:142-8. 
11. Gillespie LD, Robertson MC, Gillespie WJ, et al. Interventions for preventing falls in older people living in the community. Cochrane Database Syst Rev 2012;(9):CD007146.

12. El-Khoury F, Cassou B, Charles MA, Dargent-Molina P. The effect of fall prevention exercise programmes on fall induced injuries in community dwelling older adults: systematic review and meta-analysis of randomised controlled trials. BMJ 2013;347:f6234.

13. Gardner MM, Robertson MC, Campbell AJ. Exercise in preventing falls and fall related injuries in older people: a review of randomised controlled trials. Br J Sports Med 2000;34:7-17.

14. Wolf SL, Barnhart HX, Kutner NG, McNeely E, Coogler C, Xu T; Atlanta FICSIT Group. Selected as the best paper in the 1990s: Reducing frailty and falls in older persons: an investigation of tai chi and computerized balance training. J Am Geriatr Soc 2003;51:1794-803.

15. Hackney ME, Wolf SL. Impact of Tai Chi Chu'an practice on balance and mobility in older adults: an integrative review of 20 years of research. J Geriatr Phys Ther 2014;37:127-35.

16. Woo J, Hong A, Lau E, Lynn H. A randomised controlled trial of Tai Chi and resistance exercise on bone health, muscle strength and balance in community-living elderly people. Age Ageing 2007;36:262-8.

17. Hammond T, Wilson A. Polypharmacy and falls in the elderly: a literature review. Nurs Midwifery Stud 2013;2:171-5

18. de Vries OJ, Peeters G, Elders P, et al. The elimination half-life of benzodiazepines and fall risk: two prospective observational studies. Age Ageing 2013;42:764-70.

19. Fick DM, Cooper JW, Wade WE, Waller JL, Maclean JR, Beers $\mathrm{MH}$. Updating the Beers criteria for potentially inappropriate medication use in older adults: results of a US consensus panel of experts. Arch Intern Med 2003;163:2716-24.

20. Campbell AJ, Robertson MC, Gardner MM, Norton RN, Buchner DM. Psychotropic medication withdrawa and a home-based exercise program to prevent falls: a randomized, controlled trial. J Am Geriatr Soc 1999;47:8503.

21. McKiernan FE. A simple gait-stabilizing device reduces outdoor falls and nonserious injurious falls in fallprone older people during the winter. J Am Geriatr Soc 2005;53:943-7.

22. Menant JC, Steele JR, Menz HB, Munro BJ, Lord SR. Optimizing footwear for older people at risk of falls. J Rehabil Res Dev 2008;45:1167-81.

23. Spink MJ, Menz HB, Fotoohabadi MR, et al. Effectiveness of a multifaceted podiatry intervention to prevent falls in community dwelling older people with disabling foot pain randomised controlled trial. BMJ 2011;342:d3411.

24. Bischoff-Ferrari HA, Dawson-Hughes B, Staehelin HB, et al. Fall prevention with supplemental and active forms of vitamin D: a meta-analysis of randomised controlled trials. BMJ 2009;339:b3692.

25. Lord SR. Visual risk factors for falls in older people. Age Ageing 2006;35 Suppl 2:ii42-ii45.

26. Harwood RH, Foss AJ, Osborn F, Gregson RM, Zaman A Masud T. Falls and health status in elderly women following first eye cataract surgery: a randomised controlled trial. $\mathrm{Br}$ J Ophthalmol 2005;89:53-9.
27. Foss AJ, Harwood RH, Osborn F, Gregson RM, Zaman A, Masud T. Falls and health status in elderly women following second eye cataract surgery: a randomised controlled trial. Age Ageing 2006;35:66-71.

28. Cumming RG, Ivers R, Clemson L, et al. Improving vision to prevent falls in frail older people: a randomized trial. J Am Geriatr Soc 2007;55:175-81.

29. Lord SR, Dayhew J, Howland A. Multifocal glasses impair edge-contrast sensitivity and depth perception and increase the risk of falls in older people. J Am Geriatr Soc 2002;50:1760-6

30. Brian JC, Potter JF. Cardiovascular causes of falls. Age and Ageing 2001;30 Suppl 4:19-24.

31. Ryan DJ, Nick S, Colette SM, Roseanne K. Carotid sinus syndrome, should we pace? A multicentre, randomised control trial (Safepace 2). Heart 2010;96:347-51.

32. Kenny RA, Richardson DA, Steen N, Bexton RS, Shaw FE, Bond J. Carotid sinus syndrome: a modifiable risk factor for nonaccidental falls in older adults (SAFE PACE). J Am Coll Cardiol 2001;38:1491-6.

33. Day LM. Fall prevention programs for community-dwelling older people should primarily target a multifactorial intervention rather than exercise as a single intervention. J Am Geriatr Soc 2013;61:284-5; discussion 285-6.

34. Russell MA, Hill KD, Day LM, et al. A randomized controlled trial of a multifactorial falls prevention intervention for older fallers presenting to emergency departments. J Am Geriatr Soc 2010;58:2265-74.

35. Tan PJ, Khoo EM, Chinna K, Hill KD, Poi PJ, Tan MP. An individually-tailored multifactorial intervention program for older fallers in a middle-income developing country: Malaysian Falls Assessment and Intervention Trial (MyFAIT). BMC Geriatr 2014;14:78

36. Osteoporosis Society of Hong Kong (OSHK). 2013 OSHK Guideline for Clinical Management of Postmenopausal Osteoporosis in Hong Kong. Hong Kong Med J 2013;19(Supplement 2):S1-40.

37. Michieli R, Carraro AM. General Practitioner and FRAX $\left(^{\circledR}\right)$ (computer-based algorithm). Clin Cases Miner Bone Metab 2014;11:120-2

38. Gillespie WJ, Gillespie LD, Parker MJ. Hip protectors for preventing hip fractures in older people. Cochrane Database Syst Rev 2010;(10):CD001255.

39. Sawka AM, Boulos P, Beattie K, et al. Do hip protectors decrease the risk of hip fracture in institutional and community-dwelling elderly? A systematic review and meta-analysis of randomized controlled trials. Osteoporos Int 2005;16:1461-74.

40. Woo J, Sum C, Yiu HH, Ip K, Chung L, Ho L. Efficacy of a specially designed hip protector for hip fracture prevention and compliance with use in elderly Hong Kong Chinese. Clin Rehabil 2003;17:203-5.

41. Santesso N, Carrasco-Labra A, Brignardello-Petersen R. Hip protectors for preventing hip fractures in older people. Cochrane Database Syst Rev 2014;(3):CD001255.

42. Cameron ID, Gillespie LD, Robertson MC, et al. Interventions for preventing falls in older people in care facilities and hospitals. Cochrane Database Syst Rev 2012;(12):CD005465.

43. Morse JM, Morse R, Tylko S. Development of a scale to identify the fall-prone patient. Can J Aging 1989;8:366-77.

44. Oliver D, Britton M, Seed P, Martin FC, Hopper AH. Development and evaluation of evidence based risk 
assessment tool (STRATIFY) to predict which elderly inpatients will fall: case-control and cohort studies. BMJ 1997;315:1049-53.

45. Meyer G, Köpke S, Haastert B, Mühlhauser I. Comparison of a fall risk assessment tool with nurses' judgement alone: a cluster-randomised controlled trial. Age Ageing 2009;38:417-23.

46. Chan DK, Diu E, Loh F. Pilot study into impaired judgement, self-toileting behaviour in fallers and nonfallers. Eur J Ageing 2013;10:257-60.

47. Australian Commission on Safety and Quality in Healthcare. Preventing falls and harm from falls in older people. Best practice guidelines for Australian hospitals and residential aged care facilities. In: Canberra (Australia): Australian Commission on Safety and Quality in Healthcare; 2009.

48. Kwok T, Bai X, Chui MY, et al. Effect of physical restraint reduction on older patients' hospital length of stay. J Am
Med Dir Assoc 2012;13:645-50.

49. Becker C, Rapp K. Fall prevention in nursing homes. Clin Geriatr Med 2010;26:693-704.

50. Jensen LE, Padilla R. Effectiveness of interventions to prevent falls in people with Alzheimer's disease and related dementias. Am J Occup Ther 2011;65:532-40.

51. Luk JK, Chiu PK, Chu LW. Rehabilitation of older Chinese patients with different cognitive functions: how do they differ in outcome? Arch Phys Med Rehabil 2008;89:1714-9. 52. Oliver D, Connelly JB, Victor CR, et al. Strategies to prevent falls and fractures in hospitals and care homes and effect of cognitive impairment: systematic review and meta-analyses. BMJ 2007;334:82.

53. Neyens JC, Dijcks BP, Twisk J, et al. A multifactorial intervention for the prevention of falls in psychogeriatric nursing home patients, a randomised controlled trial (RCT). Age Ageing 2009;38:194-9. 